\title{
Identification of Climate and Psammotherapy Results at Tavan Els Kidney Sanatorium in the Western Mongolia
}

\author{
L. Javzmaa1, G. Purevdorj'2, S. Khishigjargal'2, B. Suvdantsetseg², J. Suvdmaa1, N. Baigalmaa1, \\ T. Tsermaa1, B. Bota1 ${ }^{1}$ J. Jargal ${ }^{1}$, 0. Munkhjargal ${ }^{1}$ \\ ${ }^{1}$ Govi-Altai Medical School of Mongolian National University of Medical Science, Ulaanbaatar, Mongolia \\ ${ }^{2}$ Tavan Els Sanatorium of Gobi-Altai Province of Mongolia, Gobi-Altai, Mongolia \\ Email: Javzmaa@mnums.edu.mn,munkhjargal@mnums.edu.mn
}

How to cite this paper: Javzmaa, L., Purevdorj, G., Khishigjargal, S., Suvdantsetseg, B., Suvdmaa, J., Baigalmaa, N., Tsermaa, T., Bota, B., Jargal, J. and Munkhjargal, O. (2020) Identification of Climate and Psammotherapy Results at Tavan Els Kidney Sanatorium in the Western Mongolia. Open Journal of Applied Sciences, 10, 719-724.

https://doi.org/10.4236/ojapps.2020.1011050

Received: October 26, 2020

Accepted: November 21, 2020

Published: November 24, 2020

Copyright (๑) 2020 by author(s) and Scientific Research Publishing Inc. This work is licensed under the Creative Commons Attribution International License (CC BY 4.0).

http://creativecommons.org/licenses/by/4.0/ (c) (i) Open Access

\begin{abstract}
In this study, we have presented the climate and psamotherapy results at the Tavan Els Kidney Sanatorium of Mongolia. Patient variety for 10 years, since 2001-2011 there admitted 2000 patients in their remission of chronic kidney illness. Contents of renal diseases diagnoses are as following: glomerulonephritis $52 \%$, phylonephritis $35 \%$, hydronephrosis $3 \%$, obstructive renal disease $2 \%$, chronic renal failure $7 \%$ and debatic nephropathy $1 \%$. Sand sauna therapy is lain into heated sand baths for adults 8 to 20 mins and for child 7 to 15 mins long, and it is performed twice a day (morning and afternoon) for 2 or 3 weeks once a year. Particularly, the sanatorium offers a type of physiotherapy through the application of thermally warmed sand and a combination of healthy micro-bioclimate, purity of the natural environment, and the presence of fresh and healthy local foods to treat a wide range of medical conditions. The sand sauna treatment most likely affects the body by means of the sand's high temperature and the presence of chemical elements those are biologically important. Its specific climate and geographical condition of sanatorium is unique by length of sunshine, wind and content, color of sand.
\end{abstract}

\section{Keywords}

Psamotherapy, Sanatorium, Chronic Kidney Disease, Bioclimate

\section{Introduction}

Due to the factors such as Mongolian geographic feature, climate, tradition, working condition, environmental factors, birth and pregnancy, there is an increasing tendency of kidney and urinary tract illnesses in the resent years that 
can lead to serious complications including high blood pressure and kidney failure [1].

According to the National Centre for Health Development statistical records in 2011, the urinary system diseases (766.7 per population of 1000) have been one of three leading illnesses among population in the last 10 years [2].

In early 1950, a number of sanatoriums, health resorts and other facilities were established in Mongolian territories for health improvement of working population and their families. One of the well experienced health resorts is the Tavan Els kidney sanatorium that mainly focused to delay progression of chronic kidney disease (CKD), prevent or slow additional damage to the patient's kidneys, improve blood circulation, decrease the use of medicines, and educate patients about alternative therapies. In 1979, this sanatorium opened at the Biger city of Gobi-Altai province in the western Mongolia to treat patients with chronic kidney glomerulonephritis by the natural heated sand baths and other facilities. It is most popular and beautiful health resort, and people from all over the country come there to be treated for CKD or just to relax during the summer. However, it is not well known outside the country.

This unique experience at the sanatorium is urgently important for financial and emotional burden problems of population. Its public importance was noted in the Natural Sand Ecology Treatment workshop held in Ulaanbaatar by leaders of Tavan Els sanatorium, 2006. The point view of this sanatorium is to regenerate these medical facilities for the future generation and also to promote the mutual recognition of international relationship, exchange the experiences of treatment method, and to develop the scientific study on treatment output with international experienced institutions.

\section{Aim of the Research Work}

Main aims of this study are to identify the climate and geographical conditions of sanatorium and present the results of psamotherapy for 10 years at the Tavan Els sanatorium.

\section{Methods}

In this study generally we used following methods: one is field measured data sets, laboratory analysis and the other one is traditional method. The data and information were collected by research members from Keio University, National University of Mongolia and Five Sand sanatorium members.

1) To identify the climate, geology, sand properties, and geomorphological elements we used hand instruments and collection of samples from July 14 to August 24, 2008. Out of the 12 soil samples and two water samples were collected from target area that was performed to soil and geological laboratory analyses. The analysis of the soil in the laboratory included the $\mathrm{pH}$, moisture content, organic matter, soil texture contents as well as chemical concentration detection of Calcium (Ca), Zinc ( $\mathrm{Zn}$ ), Magnum (Mg), Potassium component 
(K2O), Copper $(\mathrm{Cu})$, Zinc $(\mathrm{Zn})$, Iron component $\left(\mathrm{Fe}_{2} \mathrm{O}_{3}\right)$ and some of complex elements which is important for medical.

2) To study the result of psamotherapy at the Tavan Els sanatorium we used questionnaire for patients from 2001 to 2011 in the sanatorium. Totally 2000 patients were involved in the study.

\section{Results}

The primary resources of the treatment at Tavan Els sanatorium are a practically unlimited number of sand baths, a sunny beach, a healthy micro-bioclimate, effective sunshine, fresh water, a peaceful environment, and an abundance of pure dairy products and fresh local foods. The Tavan Els magnetic sand dunes lie at the headwaters of Biger Lake in a wide valley encircled by the beautiful Mongol Altai and Khuk Serkh mountain ranges. The sand dune beaches comprise 40 to 50 barchan dunes forming a chain, from the northwest to the southeast. The chain is approximately $10 \mathrm{~km}$ long, 0.25 to $1.4 \mathrm{~km}$ wide, and 8 to $15 \mathrm{~m}$ high. The macroclimate of the Tavan Els area is characterized as continental, harsh, desert that is dry, salty, and warm [1]. Biger city is called the "fire land," and in summer the air temperature usually reaches up to $25.5^{\circ} \mathrm{C}$ and the surface of the sand dunes exceeds $50^{\circ} \mathrm{C}$, making the microclimate very favorable for balneotherapy. The average annual wind speed is $3.1 \mathrm{~m} / \mathrm{s}$, mostly from the north and northwest; this is best for sand bathing on the southern slopes of the sand dunes. The sand is clear coarse, alluvial silts and golden yellow. The specific geomorphological characteristics of the sand dunes are listed in Table 1.

Table 1. Geomorphologic component of the Tavan Els sand dunes.

\begin{tabular}{cc}
\hline Geomorphologic component of the Tavan Els sand dunes \\
\hline Component & Measurement \\
\hline Latitude & $45^{\circ} 73^{\prime} \mathrm{N}$ \\
Longitude & $97^{\circ} 33^{\prime} \mathrm{E}$ \\
Geology & Alluvial silts \\
Ave.annual precipitation & $66.9 \mathrm{~mm}$ \\
Ave. annual air temp. & $25.5^{\circ} \mathrm{C}$ \\
Ave. annual sand temp. & $50^{\circ} \mathrm{C}$ \\
Wind speed & $3.1 \mathrm{~m} / \mathrm{s}$ \\
Elevation & $1318-1333 \mathrm{~m}$ \\
No. of dunes & $40-50$ \\
Color & Golden-yellow \\
Ave. grain size & $0.25 \mathrm{~mm}$ \\
Direction & $\mathrm{NNW}-\mathrm{SSE}$ \\
Aspect & $160^{\circ}-180^{\circ}$ \\
Slope & $29^{\circ}-32^{\circ}$ \\
Height & $8-15 \mathrm{~m}$ \\
Width & $0.25-1.4 \mathrm{~km}$ \\
Length & $10 \mathrm{~km}$ \\
Ph & 7.89 \\
\hline & \\
\hline &
\end{tabular}


As a result of our investigation, the sands of Tavan Els are materials of continental origin. The sand fraction is dominated by fine sand material (<70\%: $0.05-0.25$ $\mathrm{mm}$ ) with small amounts of course sand, silt and clay size particles (>20\%: $0.25-1$ $\mathrm{mm}$; >3\%: $0.001-0.05 \mathrm{~mm} ;>5 \%$ : $<0.001 \mathrm{~mm}$ ) in Table 2. The moisture content of sand in the dunes is variable, ranging from $0.08 \%$ to $10.9 \%$ and particularly it is dry in the main dunes which used for sand bathing but in the near river area is wet. Organic matter $(\mathrm{OM})$ concentrations are relatively low (average $0.25 \% \pm 0.09 \%$ ). The chemical composition of the Tavan Els sand was composed of following oxides $\mathrm{SiO}_{2}$ (68.21\%), $\mathrm{Al}_{2} \mathrm{O}_{3}$ (13.55\%), $\mathrm{CaO}$ (4.2\%), $\mathrm{MgO}$ (1.73\%), $\mathrm{MnO}$ (0.06\%), $\mathrm{P}_{2} \mathrm{O}_{5}$ (0.07\%), $\mathrm{TiO}_{2}(0.33 \%), \mathrm{Fe}_{2} \mathrm{O}_{3}(3.69 \%), \mathrm{Na}_{2} \mathrm{O}(3.55 \%)$ and $\mathrm{K}_{2} \mathrm{O}(2.11 \%)$.

The therapeutic success of sand bathing is based on traditional and practical healing practices and the systematic use of bioclimatic environments. This study selected 150 patients with chronic glomerulonephritis symptoms of swelling $31 \%$ hematuria 9\%, hypertension (over 140/90mmHg) 10\% and mixed conditions $50 \%$. There is significant differences after treatment that the chronic low back pain was decreased $78.6 \%$ to $37 \%$, fatigue $41 \%$ to $33 \%$, headache $19.6 \%$ to $9 \%$, and swelling $11 \%$ to $1.8 \%$. After the 10 days treatment, the proteinuria was decreased in 78 patients (52.6\%), and hematuria decreased in 25 (16.6\%) from the total number of patients. And, 72 (48\%) patients decreased oedema, 52 (34.6\%) patients hypertension decreased $10 \pm 5$, in 30 (20\%) patients decreased $20 \pm 5$ and $45 \%$ of patients did not changed. A swelling was disappeared $51 \%, 38 \%$ decreased and $3 \%$ not changed. $66 \%$ of patients down the weight loss about $2-4$ $\mathrm{kg}$, and $34 \%$ of patients not changed. We observed typical changes during 15 50 minutes bathing, heart rate increased from $65 \pm 1.3 \mathrm{bpm}$ at rest to $82 \pm 2.4$ $\mathrm{bpm}$ in $45^{\circ} \mathrm{C}$ hot sand bath. Blood pressure increased from $132 \pm 4.0 / 82 \pm 2.2$ $\mathrm{mmHg}$ at rest to $139 \pm 1.4 / 81 \pm 1.0$ at the bathing. Body temperature was increased $1^{\circ} \mathrm{C}-2^{\circ} \mathrm{C}$ during bathing after our physical examination and it verified that it increases the secretion of sweating and improves kidney function.

\section{Discussion}

Our study presented the effect of meteorological variables o result of psamotherapy at the Tavan Els sanatorium that such as wind and amounts of sunshine and rain had effects on sand sauna therapy, because the treatment elements are based on natural resources that are strongly affected by climatic conditions.

Table 2. The average of grain-size together with texture and mineralogical characters in the Tavan Els sand.

\begin{tabular}{|c|c|c|c|c|c|c|c|c|c|c|}
\hline Statistic profile & $\begin{array}{l}\text { Sand course } \\
0.25-1 \mathrm{~mm}\end{array}$ & $\begin{array}{c}\text { Sand fine } \\
0.05-0.25 \mathrm{~mm}\end{array}$ & $\begin{array}{c}\text { Silt } \\
0.001-0.05 \mathrm{~mm}\end{array}$ & $\begin{array}{c}\text { Clay } \\
<0.001 \mathrm{~mm}\end{array}$ & Moisture & $O M$ & $\mathrm{CaCO}_{3}$ & $p H$ & $\mathrm{Ca}$ & $M g$ \\
\hline & & & $\%$ & & & & & water & \multicolumn{2}{|c|}{$\mathrm{meq} / 100 \mathrm{~g}$} \\
\hline $\begin{array}{l}\text { Overall average } \\
\qquad(\mathrm{n}=12)\end{array}$ & 19.9 & 72 & 3.32 & 4.7 & 4.14 & 0.25 & 3.84 & 7.89 & 13.2 & 7.9 \\
\hline $\mathrm{SD}$ & 20.5 & 21.5 & 2.9 & 1.52 & 5.17 & 0.09 & 1.41 & 0.22 & 3.44 & 4.4 \\
\hline Min & 1.74 & 52.65 & 0.88 & 2.8 & 0.08 & 0.12 & 2.9 & 7.7 & 10 & 2.4 \\
\hline Max & 42.83 & 92.98 & 7.48 & 6.48 & 10.9 & 0.33 & 5.95 & 8.22 & 17 & 13 \\
\hline
\end{tabular}


Other studies have found that the sand's and water's high temperature supports sweating, which can reduce joint swelling, increase blood circulation to the kidney and skin, and relieve pain as a result of muscle relaxation [3].

The first study of Altantsetseg. J and Namkhaijantsan. G (1995) on general condition of climate around Biger showed that the effects of heat, magnetic energy, and sand massages have been found to be comprehensively effective in sand therapy [4].

According to the study of Purevdorj G, Munkhjargal Sh, Ochir J (2006) the sands at Tavan Els contain high levels of silica, alumina, calcium, magnesium, sodium, and iron, which are biologically important elements. Sand with relatively high silica content is easily cleansed from the body. In contrast, sands rich in biotite, muscovite, and carbonium are not good for use in sand bathing, because these materials are difficult to remove from the outside of the body. The Tavan Els sand is dominated by fine sand fraction that it is very useful for balneotheraphy [5].

The most important climatic factor needed for the application of sand sauna treatment is warmth. The macroclimate of the Tavan Els area is characterized as continental, harsh, desert that is dry, salty, and warm [6].

The sand sauna treatment appears to be an effective and useful method to address some of the symptoms of CKD and possibly reduce the financial and emotional burdens faced by CKD patients and their communities.

Our study was limited to the sand therapy and local conditions at Tavan Els. More studies are needed of therapies offered at other institutions and for other diseases. In addition, it would be helpful to have studies with longer follow-up periods.

\section{Conclusions}

The Tavan Els Kidney Sanatorium offers a type of balneotherapy through the application of thermally warmed sand and a combination of climatic, environmental, and nutritional factors to treat a wide range of medical conditions without using any modern medical equipment. The curative sand dunes, variety and purity of the natural environment, unique geography, extremely favorable bioclimatic conditions, and healing traditions are unique to this sanatorium. We recommend more scientific research on the effectiveness of balneotherapy for the treatment of CKD treatment. It is also important to assess the effect of implementing treatment guidelines on the outcomes of CKD treatment.

According to those, sand sauna appears to be an effective and useful method to treat problems of patients with $\mathrm{CKD}$, problems that especially for the symptoms of high blood pressure, cause of swelling, proteinuria, infrequent urine and blood in urine as well as improvements of well being. Mainly, in patients extended remission period, increased immunity and reduced urine analyze changes and signs of edema and toxicities. Through these studies, we found a link between weather and the intensity of treatment at the sanatorium. The effect 
of heat, magnetic energy and sandy massages are comprehensively effective in sand therapy and a result of muscle relaxation pain may be relieved and also the natural thermal sands warming the human body equally through it can be clear out the edema, improve blood circulation.

It not only improves people's quality of life, but also helps to lower weight and reduce stress levels.

\section{Acknowledgements}

I would like to express my very great appreciation to Dr Batbaatar, director of Mongolian National University of Medical Science, Dr Munkhjargal and technicians of the laboratory of National University of Mongolia, Science and Technology University laboratory staff, Tavan els Sanatorium staff members, and Keio University team members for their valuable suggestions, advice and assistance during the planning and development of this research work.

\section{Conflicts of Interest}

The authors declare no conflicts of interest regarding the publication of this paper.

\section{References}

[1] Sarantsetseg, G., Batchimeg, U., Sambuudorj, D. and Sededdulam, S. (2006) Comparative Study on Urine Analysis of Traditional Medications Treatment Results on Pyelonephritis. Health Science Journal, No. 4, 66-67.

[2] Health Statistics (2011) Implementing Agency of Government. Health department, $\mathrm{p} 21$.

[3] Oyun, J. and Chimedtseren, P. (2006) The Natural Medicinal Sand Properties and Treatment Quality. In: Purevdorj, G., Munkhjargal, Sh. and Ochir, J. (Eds.), Proceedings of the Natural Sand-Ecology Treatment-Biger, Ulaanbaatar, 31-41.

[4] Namkhaijantsan, G. (1995) Proceedings of Conference on Ecological Features of Great Gobi. Ulaanbaatar, 11-12. (in Mongolian)

[5] Baasan, T. (2006) Geomorphological Conditions for Sanatorium Treatment in the Tavan Els Region. In: Purevdorj, G., Munkhjargal, Sh. and Ochir, J. (Eds.), Proceedings of the Natural Sand-Ecology Treatment-Biger, Ulaanbaatar, 29-31.

[6] Namkhaijantsan, G. and Dulamsuren, D. (2006) Result of Micro-Bio-Climate Features and Medical Bioweather Index near the Tavan Els Area. In: Purevdorj, G., Munkhjargal, Sh. and Ochir, J. (Eds.), Proceedings of the Natural Sand-Ecology Treatment-Biger, Ulaanbaatar, 11-21. 